\title{
Mineralization System with Magnetic Method in Kluwih, Pacitan, Central Java
}

\author{
$1^{\text {st }}$ Fatimah $^{1}, 2^{\text {nd }}$ Muh Isnanto $^{1}, 3^{\text {th }}$ Vergillio Asqueli $^{3}, 4^{\text {th }}$ Audi Tri Lavanto ${ }^{4}, 5^{\text {th }}$ Faisal Sangaji $^{5}$ \\ fatimah@itny.ac.id
}

Departement of Geological Engineering, Institut Teknologi Nasional Yogyakarta, Indonesia ${ }^{1,2}$ Departement of Geophysics Engineering UPN "Veteran" Yogyakarta, Indonesia 3 "4

Departement of Geological Engineering, Akprind Yogyakarta, Indonesia ${ }^{5}$

\begin{abstract}
Gold mines in Indonesia are mostly still below the surface. Pacitan and the surrounding area is the part of Eastern Southern Mountain Range that has a lot of zones of alteration which appears on the surface, with some precious metal minerals were found. Ore minerals are found disseminated sulfide ore pyrite, arseno pyrite, chalcopyrite, enargite and malachite. From measurements of geomagnetic found high magnetic anomaly less than 700 $\mathrm{nT}$ surrounded by a low magnetic values and form a circular pattern, it is an indication of the pattern of anomalies of the porphyry system that is closed by the argillic. Based on data integration of geological and geophysical the mineralization in the Pacitan area in the interpretation were in the proximal part of the high sulfide and suspicion leads to the porphyry deposits are still covered by the lithocaps.
\end{abstract}

Keyword: mineralization, Pacitan, geomagnetic

\section{Introduction}

Based on the plate tectonic theory, the magmatic path that carries mineral deposits in the Indonesian archipelago has been known and predicted. The geological mapping, completed in 1995, utilized the theory in tracking rock dispersal, concluding that in Indonesia there are 15 basic metallic mineral pathways, as the basic characteristics of mineral resources in Indonesia.

The formation of metal minerals is closely related to the magmatic process. The mineral formation environment is commonly found in volcanic rocks. This can be understood because the magmatic process takes place simultaneously with volcanic activity. As a result of intensive erosion, the magmatic rocks can surface and leave only a small amount of volcanic rock. If the erosion surface is right in the mineralized zone, the metal mineral has been exposed and is very easy to obtain.

Pacitan regency is included in the Southern Mountains Region of East Java. Regionally, Tegalombo is covered by volcanic rocks that belong to the old andesite rock formations, also known as the Besole Formation which is the oldest rock in this area. This formation is Oligocene, intruded by deda and andesite, accompanied by intercalation of cracks and gaps in quartz veins. The sequence of volcanic rocks from the north to the south of the study area, which consists of lava flows of resin and andesite, andesite breccia, pyroclastic tuff, and clastic sedimentary intercalation such as sandstones and mudstone. Jaten Formation Overlies Besole Formation, including volcanic rock as mismatch, Oligocene-Miocene age. This formation consists of quartz sandstone and mudstone, which is distributed in the southern part of the study area. Above the Jaten Formation, the Wuni Formation is deposited around the Lower Miocene. This formation is exposed in the center of the study area. The lithology of this formation consists of tuff, sandy tuff, breccias, lumps, shales and limestone lenses. The Wuni formation does not change as propylitic due to the intrusion of igneous rocks such as granodiorite, tonalite and quartz diorite. Furthermore, there is a Nampa Formation consisting 
of claystone units, sandstone and younger coal-fired intercalations. This formation is lower until the Middle Miocene (Smyth, H.R., Hall, R., Nichols, G.J., 2008).

The prospect of minerals in the Kluwih and surrounding areas has indeed been studied extensively, especially surface geology and geochemistry. For the mining prospects, it is necessary to know the subsurface picture, hence the subsurface model is performed with geophysical data, namely by geomagnetic measurements. With this geomagnetic measurement, it is expected to know the magnetic value of rocks, then after that it can be known the area of minerals and alteration. The aim is to create subsurface models from magnetic and geological data so as to obtain subsurface images for mineral exploration advice.

\section{Magnetic Method}

Geomagnetic method is one of the geophysical methods that are often used for preliminary surveys on petroleum, geothermal, mineral rock and volcanic monitoring. This method has a relatively high measurement accuracy. Instrument and operation in the field is relatively simple, easy and fast when compared with other geophysical methods. Practical reading correction is not necessary.

In general, magnetic field anomaly maps (for applied geophysics usually used total field or vertical field) are rather complex. The field variation is more erratic and localized as a result of the magnetic field of the dipole which is the vector quantity. The magnetic anomaly map shows a large number of residual anomalies (remnants) which are the result of a large variation of magnetic mineral parts contained in rocks near the surface. As a result of the foregoing, proper interpretation of the geomagnetic method is relatively more difficult.

The basis of the magnetic method is the Coulomb force between two magnetic poles $\mathrm{m} 1$ and $\mathrm{m} 2$ (e.m.u) spaced $\mathrm{r}(\mathrm{cm})$ in the form of:

$$
F=\frac{m_{1} x m_{2}}{\mu_{0} r^{2}} x r \text { (dyne) }
$$

With $\mu_{0}$ is the permeability of the medium in a vacuum, dimensionless and precious one (Dobrin, 1988).

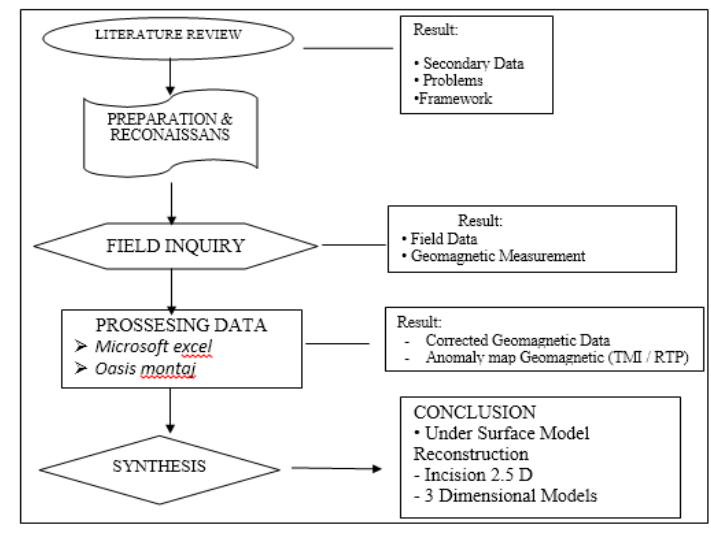

Fig. 1. Schematic diagram of research method 


\section{Methodology}

The tool used in the survey of magnetic methods is the Proton Precession Magnetometer Geometrics model G-856. PPM is a portable tool with a fairly easy and simple operating system. In the PPM research used amounted to two pieces, one as rover and one as base station. PPM can be used to measure the magnetic field of the gradient as well as the total magnetic field. Measurement of a gradient magnetic field using two sensors and a total magnetic field using one sensor. Some other aids are:

1. Theodolite, to determine the direction of the path of measurement points in the field.

2. Geological compass, to determine the north direction of the PPM sensor and to help determine the position to order.

3. GPS, to determine the position of latitude and longitude and the height of the research location.

4. Meter, to measure the distance of the grid.

5. Clock, to know the time of data retrieval in the field.

6. Field notes, to record day, date, time, weather and environmental conditions when taking data.

Data collection depends on the target and field conditions. Measurements with local targets are usually performed for a relatively small survey area, with a space of 100 meters, while for regional targets covering a larger area with a space of $1 \mathrm{~km}^{2}$ (figure 1).

Geomagnetic data processing done is upward continuation. Upward continuation is the process of transforming potential field data from a plane to another higher plane. In the processing of geomagnetic data, this process can serve as a low filter, to eliminate a reduction of local magnetic effects derived from various sources of magnetic objects scattered on topographical surfaces unrelated to the survey. The appointment process should not be too high, as it can reduce the local magnetic anomaly sourced from the magnetic object or geological structure that is the target of this magnetic survey. In many cases, the magnetic field anomaly data targeted by the survey has always been superseded or mixed with other magnetic anomalies derived from very deep and wide sources beneath the earth's surface. This magnetic anomaly is called a regional magnetic anomaly (Breiner, 1973). To interpret the magnetic field anomaly targeted by the survey, a regional effect correction is made, which aims to remove the magnetic anomaly effect of the region from the measured magnetic field anomaly data. One method that can be used to obtain regional anomalies is upward exposure to certain altitudes, in which the resulting contour anomaly map is likely to remain unchanged and no longer changing patterns when higher elevations are made.

\section{Result and Analysis}

This research focuses on use of geomagnetic data to estimate the mineralized system in Kluwih and surrounding areas, Pacitan, East Java which combine with surface geological data in this case rock alteration mapping and measurement the direction structure in the field and supported by existing geochemical data. Geomagnetic survey conducted on an area of $1 \times 1$ $\mathrm{km}$ with gridding method and space $200 \times 100$ meters.

The field geomagnetic data acquired has been processing with Microsoft Excel for correcting the magnetic data that is daily correction and IGRF correction, resulting in total magnetic intensity anomaly value. Furthermore, TMI map can be created with Oasis montaj. Data processing with Oasis montaj uses some filtering, such as upward continuation and reduce to pole (RTP). This step is done so the resulting magnetic map approaches real geology conditions in the field and ready to be interpreted. This stage is carried out to create 3D models and 2.5 D sections to be able to estimate the shape and depth of a subsurface model 
that related with the occurence of mineralization in the research area. Figure 2 is a Reduce To Pole (RTP) Map and lithologic interpretation results with field photo of outcrop in the research area (left picture), a full 3D model, half 3D model (low and high intensity magnetic) and section $2.5 \mathrm{D}$ (right picture). Generally shows high, medium, and low magnetic intensity values.

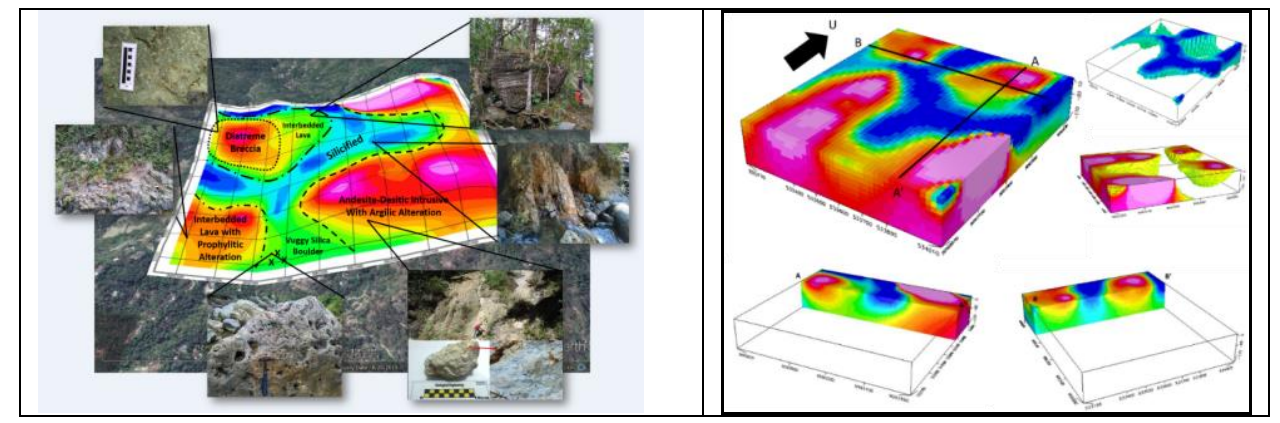

Fig. 2. Magnetic mapping with geological mapping

From the geological and geomagnetic mapping of the South Intensity magnetism $72.9 \mathrm{nT}$ - 519.4 nT lithology The fresh (intrusive) Andesite dominates the geology of the research area presumed to be a rock host that causes an argilic alteration that closes predominantly at the top of the andesite intrusion, in this alteration has begun to appear metal minerals such as pyrite (disseminated), still cannot change the value of significant magnetism because it is more dominated by clay minerals formed (kaolinite-illite). In the middle Intensity of magnetism $194.7 \mathrm{nT}-(-240.1) \mathrm{nT}$ Silicified alteration is present in the direction of the river that is suspected to be formed due to the relatively NE-SW and W-E structures. In the north Intensity of magnetism -247.4 nT - (-340.1) nT. The lithology is a silicified alteration that is present in the direction of a river that is suspected to be formed due to the relatively NE-SW and W-E structures. In the north Intensity magnetism -72.9 nT - 279.8 nT Lava andesite fresh, alteration weak (figure 2).

The prospect of mineralization in the Kluwih region is found in the andesite-dasitic intrusion which is a volcanic body part of the eroded Sunda-Banda magmatic archipelago of Oligo-Miocene. In the study area developed extensional structure that resulted in the existence of fractures (open space) so as to enable epithermal type veins (veins) is formed (figure 3). Minerals sulphides are formed in the area Kluwih Pacitan is a type of vein zone, associated with quartz, partially spread unevenly inside alteration rock zone. In some locations adjacent to the quartz vein zone, found in limited interlocking quartz veins cut or stockwork type, sometimes contain sulfides. (Sudarsono, 2009). The extensional structure has NE-SW and E$\mathrm{W}$ directions. This fracture becomes the solution of the hydrothermal solution from the earth that causes the surrounding rock to be altered. The types of alterations found in the field are silicified, argillic, and prophylitic. The location of mineralized formation in the Kluwih area is in the medial volcanic setting. Ore deposits are commonly found with stock work structures. The veins that fill the rock fractures are dominated by quartz minerals, pyrite, chalcopyrite, which contain ore minerals of economic value primarily copper $(\mathrm{Cu})$ and lead $(\mathrm{Pb})$. 


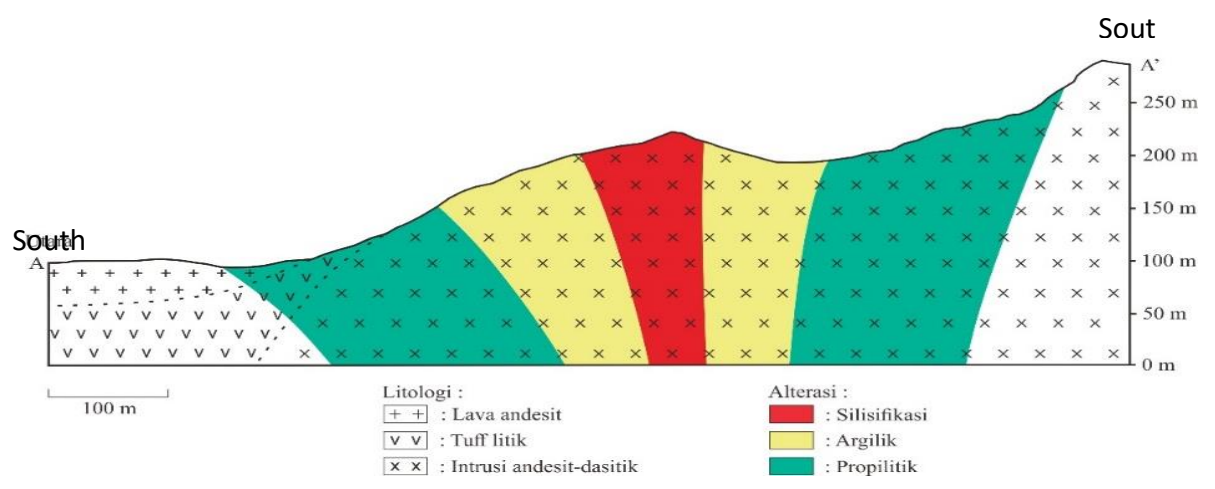

Fig. 3. The subsurface model of Kluwih area, Pacitan, East Java based on geomagnetic analysis

\section{Conclusions}

1. The study area is in the volcano of Oligo-Miocene so that it has high magnetic intensity value, but in some locations it is found that the low intensity of magnetism is due to the hydrothermal solution which causes the teralteration rocks.

2. The anomalous value on the Reduce To Pole map ranges from $519.4 \mathrm{nT}$ to $-340.1 \mathrm{nT}$.

3. The lithology obtained is fresh andesite-dasitic frozen and altered silicified, argillic, to propylitic, lytic tuff, and andesite lava.

4. The geological structure of the study area is dominated by the extensional structure with the NE-SW and E-W directions being the main trap of the epithermal vein of the main mineral ore mineralization of copper $(\mathrm{Cu})$ and lead $(\mathrm{Pb})$.

5. From the predicted subsurface picture of Kluwih Pacitan type mineralization region is high sulfide and leads to porphyry deposit

\section{References}

[1] Breiner, S., 1973, Applications Manual for Portable Magnetometers, Geometrics,USA Dobrin, M. B. N. Safid, 1988, Introduction to Geophysical Prospecting Edisi IV, Mc Grow Hillco, New York, San Fransisco

[2] Smyth, H.R., Hall, R., Nichols, G.J., 2008a. Cenozoic volcanic arc history of East Java, Indonesia: the stratigraphic record of eruptions on an active continental margin. In: Draut, A., Clift, P.D., Scholl, D.W. (Eds.), Formation and Applications of the Sedimentary Record in Arc Collision Zones: Special Paper. Geological Society of America Boulder, pp. 199-222.

[3] Sudarsono, Indarto, S., Setiawan, I., Fauzi, A., dan Listyowati, 2009, Model Genesa Mineralisasi Hidrotermal Daerah Pacitan, Jawa Timur, Prosiding Pemaparan Hasil Penelitian Puslit Geoteknologi Bandung 